\title{
REACTIVE POWDER CONCRETE DENGAN SUMBER SILIKA DARI LIMBAH BAHAN ORGANIK
}

\author{
Yulius Rief Alkhaly \\ Jurusan Teknik Sipil, Fakultas Teknik, Universitas Malikussaleh \\ Email:yr.alkhaly@gmail.com
}

\begin{abstract}
Abstrak
Reactive powder concrete (RPC) merupakan varian baru dari beton mutu ultra tingggi (ultra high strength concrete) yang diperkenalkan kepada umum pertama kali pada tahun 1994. Beton modern ini memiliki beberapa keunggulan dibandingkan beton konvensional (normal concrete) atau beton kinerja tinggi (high performance concretes). Penelitian tentang RPC di Indonesi masih sangat terbatas, RPC pertama bermaterial lokal Indonesia dikembangkan tahun 2009, dengan sumber silika berasal dari silica fume. Sebagai bagian dari berbagai penelitian lanjutan tentang RPC, hasil akhir dari riset ini diharapkan dapat menghasilkan RPC yang benar-benar sesuai dengan karakteristik material di Indonesia. Sumber silika yang digunakan berasal dari limbah bahan organik sehingga dapat menekan biaya produksi dan menghasilan green concrete yang dapat mengurangi dampak negatif limbah terhadap lingkungan.
\end{abstract}

Kata kunci: Reactive Powder Concrete, Silika, Limbah Bahan Organik

\section{Pendahuluan}

Reactive Powder Concrete (RPC) termasuk dalam jenis beton paling mutakhir yang dikembangkan untuk memenuhi kebutuhan akan material konstruksi beton berkekuatan tinggi. RPC merupakan Ultra High Performance Concrete (UHPC) atau Ultra High Strength Concrete (UHSC) yang mempunyai karakteristik sebagai material sangat padat dengan kuat tekannya mencapai 800 MPa. Kekuatan yang sangat tinggi tersebut dapat dicapai karena faktor air semen (fas) yang digunakan pada campuran RPC bernilai ekstrim rendah $(0,15-0,26)$, dan dilakukan optimalisasi struktur-micro matriks beton dengan gradasi material berukuran nano $(\mathrm{nm})$ yang berguna untuk meminimalkan rongga kosong antara butiran/partikel sehingga didapat matriks beton yang ultra padat. Perencanaan gradasi untuk mendapatkan kepadatan optimal tersebut diistilahkan sebagai Packing density. Berhubung nilai fas yang digunakan ekstrim rendah, maka dibutuhkan superplastisizer, agar beton segar RPC dapat dikerjakan dengan kelecakan (workability) yang baik. Selain itu, RPC mengandung bahan tambah berupa silica fume dalam jumlah besar $(23-25 \%$ dari berat semen) yang rekasi kimianya menghasilkan kekuatan tambahan pada beton [5],[6],[8],[24],[32]. Dengan demikian, diketahui bahwa campuran RPC berbeda dengan beton konvensional, karena RPC pada dasarnya meniadakan penggunaan agregat kasar dan ukuran partikel material pembentuk berada pada skala nanometer.

Kuat tekan beton yang sangat tinggi berkorelasi dengan sifat getas beton (brittle), tetapi hal ini dapat diminimalkan dengan penambahan serat baja sehingga diperoleh struktur RPC yang bersifat daktail dengan dimensi struktur yang ramping, bobot struktur yang ringan, dan dapat memikul beban sekuat baja [11].

Reactive Powder Concrete Dengan Sumber Silika Dari Limbah Bahan Organik- 
RPC pertama kali dikembangkan pada awal tahun 1990 oleh P. Richard dan M. Cheyrezy pada Laboratorium Bouyques, Lafarge Group, di Perancis. Selanjutnya, guna pemasaran RPC hasil riset tersebut, RPC telah diproduksi secara komersial dengan merek industri Ductal ${ }^{\circledR}$. Kuat tekan RPC komersial ini dapat mencapai lebih-kurang $150 \mathrm{MPa}$ [16]. Selain Ductal ${ }^{\circledR}$, merek-merek komersial dari berbagai industri lainnya telah pula muncul, antara lain: Densit ${ }^{\circledR}$ (Denmark), Caracem ${ }^{\circledR}$ (Swiss, Perancis), Ducon ${ }^{\circledR}$ (Jerman) dan Dura ${ }^{\circledR}$ (Malaysia) [13].

Pada beberapa tahun belakang ini, banyak riset yang telah dilakukan oleh peneliti dari berbagai negara guna menghasilkan beton dengan kuat tekan dan kinerja tinggi menggunakan bahan-bahan lokal [1], [5], [10], [13], [16], [17], [18], [27], tanpa bergantung pada merek industri tertentu. Penggunaan bahan alternatif pengganti silica fume, sebagai sumber silika seperti: ground granulated blast furnace slag, fly ash [17],[29],[32], dan abu sekam padi (rice husk ash) [2] pada campuran RPC memberikan kuat tekan dan kinerja yang memenuhi kriteria hampir setara dengan RPC bermaterial silica fume. Sedangkan di Indonesia, karena masih terbatasnya penelitian tentang RPC, terutama yang harus dikembangkan adalah rancangan campuran yang menggunakan bahan-bahan lokal yang ada [11], agar dapat dihasilkan RPC yang benar-benar sesuai dengan karakteristik material di Indonesia. Pada tahun 2009, telah berhasil dikembangkan UHPC (atau RPC) pertama dengan material lokal Indonesia, berbasis pada teknologi nano dengan sumber silika juga berasal dari silica fume. Kuat tekan yang dihasilkan berkisar antara $130 \mathrm{MPa}$ sampai $140 \mathrm{MPa}$ [12].

Biaya produksi RPC yang umumnya mahal, pemanfaatan pozzolan limbah organik untuk menggantikan silica fume dan limbah kaca untuk menggantikan tepung kuarsa sebagai bahan campuran RPC akan dapat menekan biaya produksi, serta mengurangi dampak negatif yang ditimbulkan limbah terhadap lingkungan.

\section{Tinjauan Kepustakaan}

\subsection{Prinsip dasar pembuatan RPC}

Pembuatan RPC dilakukan dengan beberapa prinsip dasar sebagai berikut [22],[24]:

a. Peniadaan agregat kasar untuk meningkatkan homogenitas beton;

b. Penggunaan silica fume untuk reaksi pozzolanik;

c. Optimalisasi campuran material granular agar terjadi peningkatan kerapatan dan terbentuknya matriks beton ultra padat;

d. Penerapan tekanan pada beton segar untuk memperoleh pemadatan terbaik;

e. Perawatan dengan panas dalam jangka waktu panjang untuk meningkatkan sifat mekanis struktur-mikro, mempercepat proses susut dan pengeringan, hal ini menghasilkan stabilitas volume, sifat rangkak minim, dan sifat susut dapat diabaikan.

f. Penambahan serat baja mutu tinggi untuk memperbaiki daktilitas dan kekuatan tarik, meningkatkan daya tahan tumbukan dan keausan, serta retak-mikro dapat diatasi secara lebih efektif. 
g. Penggunaan faktor air semen ekstrim rendah guna mengurangi jumlah poripori dan kapiler sehingga impermeabilitas meningkat yang menghasilkan durabilitas dan kekuatan superior;

h. Penggunaan superplastisizer dalam dosis tinggi guna memperoleh kelecakan/ kemudahan kerja (workability) yang baik.

\subsection{Komposisi campuran RPC}

Tipikal komposisi dari material penyusun RPC secara spesifik terdiri atas [24]:

a. Semen (cement): jenis semen portland tipe I/II, yang terbaik adalah semen yang mempunyai kandungan C3A (Tricalcium aluminate) paling sedikit [11]. Ukuran partikel semen $1 \mu \mathrm{m}-100 \mu \mathrm{m}$;

b. silica fume: bersih dari kotoran dengan ukuran partikel $0,1 \mu \mathrm{m}-1 \mu \mathrm{m}$;

c. superplastisizer: berbahan dasar Polycarboxyltatehter (PCE) akan memberikan tingkat workability yang terbaik [11];

d. pasir kuarsa (quartz sand): ukuran partikel $150 \mu \mathrm{m}-600 \mu \mathrm{m}$;

e. serbuk/tepung kuarsa (crushed quartz/quartz powder): berjenis crystalline dengan ukuran partikel $5 \mu \mathrm{m}-25 \mu \mathrm{m}$;

f. serat baja (steel frber) (optional): berbentuk lurus dengan diameter $0,15 \mathrm{~mm}-$ $0,2 \mathrm{~mm}$, panjang antara $10-25 \mathrm{~mm}$.

Komposisi campuran RPC berdasarkan berat material dari beberapa peneliti terdahulu diperlihatkan dalam Tabel 1.

Tabel 1: Komposisi material RPC dari peneliti terdahulu

\begin{tabular}{|c|c|c|c|c|c|c|c|c|}
\hline Constituent & \multicolumn{3}{|c|}{$\begin{array}{c}\text { Richard and Cheyrezy } \\
(1995)\end{array}$} & $\begin{array}{c}\text { Matte \& } \\
\text { Moranville } \\
(1999)[19]\end{array}$ & $\begin{array}{c}\text { Habel, } \\
\text { et. al } \\
(2006)[10]\end{array}$ & $\begin{array}{c}\text { Louis } \\
(2010)[18]\end{array}$ & $\begin{array}{c}\text { Tam, } \\
\text { at.al (2012) } \\
\text { [27] }\end{array}$ \\
\hline & \multicolumn{2}{|c|}{ Plain } & $\begin{array}{c}\text { Steel fibers } \\
(13 \mathrm{~mm})\end{array}$ & Steel fibers & $\begin{array}{c}\text { Steel fibers } \\
(10 \mathrm{~mm})\end{array}$ & $\begin{array}{c}\text { Steel fibers } \\
(13 \mathrm{~mm})\end{array}$ & Plain \\
\hline Portland cement & 1 & 1 & 1 & 1 & 1 & 1 & 1 & 1 \\
\hline Silica fume & 0,25 & 0,23 & 0,25 & 0,23 & 0,325 & 0,26 & 0,21 & 0,325 \\
\hline Quartz Sand & 1,1 & 1,1 & 1,1 & 1,1 & 1,43 & 0,7 & - & 1,43 \\
\hline Crushed quartz & - & 0,39 & - & 0,39 & 0,3 & - & - & 0,3 \\
\hline Glass Sand & - & - & - & - & - & - & 1,032 & - \\
\hline Superplasticizer & 0,016 & 0,019 & 0,016 & 0,019 & 0,018 & 0,018 & 0,08 & 0,025 \\
\hline Steel fibers & - & - & 0,175 & 0,175 & 0,275 & 0,45 & 0,21 & - \\
\hline Water & 0,15 & 0,17 & 0,17 & 0,19 & 0,2 & 0,18 & 0,26 & 0,265 \\
\hline $\begin{array}{c}\text { Pre-setting } \\
\text { pressure, } \\
\text { MPa }\end{array}$ & - & - & - & - & - & - & - & - \\
\hline $\begin{array}{c}\text { Post-setting } \\
\text { heat treatment } \\
\text { temperature, }{ }^{\circ} \mathrm{C}\end{array}$ & 20 & 90 & 20 & 90 & 90 & 20 & 20 & 27 \\
\hline $\begin{array}{c}\text { Compressive } \\
\text { strength, MPa }\end{array}$ & \multicolumn{2}{|c|}{$170-230$} & & 216 & 168 & 128 & 145 \\
\hline
\end{tabular}

\subsection{Sifat-Sifat Mekanis dan Durabilitas RPC}

Kuat tekan dan kinerja RPC sangat tergantung pada bahan baku, proporsi material, jenis perawatan (curing) dan kontrol kualitas keseluruhan produksi [9],[30],[32]. RPC memiliki kuat tekan antara $120 \mathrm{MPa}-800 \mathrm{MPa}$ dengan 
modulus elestisitas antara $30 \mathrm{GPa}-75 \mathrm{GPa}$ dan kuat tarik lentur berkisar $22 \mathrm{MPa}$ - $141 \mathrm{MPa}[10],[18]$.

RPC memiliki durabilitas ultra tinggi yang dihasilkan dari ekstrim rendahnya porositas matriks beton. Penetrasi ion klorida rata-rata lebih rendah 25 kali dibanding HPC, absorpsi air rata-rata 4 kali lebih rendah dibanding HPC dan kehilangan bobot akibat penetrasi asam/sulfat rata-rata 2,5 kali lebih rendah dibanding HPC [19].

\subsection{Sumber Silika Dari Bahan Organik}

\subsubsection{Abu Sekam Padi}

Abu sekam padi merupakan hasil pembakaran dari kulit padi berwarna keabu-abuan pada kondisi alami. Abu sekam padi mengandung silika $\left(\mathrm{SiO}_{2}\right) 90 \%$ $-95 \%$ setelah pembakaran 24 jam pada temperatur $600{ }^{\circ} \mathrm{C}-800{ }^{\circ} \mathrm{C}$ [15]. Tabel 2 memperlihatkan bahwa kandungan silika dalam abu sekam padi lebih tinggi dibanding semen.

Tabel 2: Komposisi kandungan kimia semen dan abu sekam padi

\begin{tabular}{|c|c|c|c|c|c|c|c|c|c|}
\hline $\begin{array}{c}\text { Komposisi } \\
\text { kimia }\end{array}$ & $\mathrm{SiO}_{2}$ & $\mathrm{Al}_{2} \mathrm{O}_{3}$ & $\mathrm{Fe}_{2} \mathrm{O}_{3}$ & $\mathrm{MgO}$ & $\mathrm{CaO}$ & $\mathrm{Na}_{2} \mathrm{O}$ & $\mathrm{K}_{2} \mathrm{O}$ & $\mathrm{SO} 3$ & LOI \\
\hline Semen & 15,05 & 2,56 & 4,00 & 1,27 & 72,17 & 0,08 & 0,41 & 2,90 & 1,33 \\
\hline $\begin{array}{c}\text { Abu sekam } \\
\text { padi }\end{array}$ & 96,70 & 1,01 & 0,05 & 0,19 & 0,49 & 0,26 & 0,91 & - & 4.81 \\
\hline
\end{tabular}

Sumber: Kartini. K, 2011.

Penggunaan abu sekam padi dalam campuran beton akan meningkatkan kemudahan kerja (workability), menurunkan retak thermal dan susut plastis. Selain itu, abu sekam juga meningkatkan kekuatan, impermaebilitas dan durabilitas beton [20]. Abus sekam padi dapat mensubstusi berat semen sebesar $30-40 \%$ [15].

\subsubsection{Abu Canggkang Kelapa Sawit}

Abu canggkang kelapa sawit punya potensi yang cukup baik sebagai material pozzolan dalam campuran beton apabila kehalusannya ditingkatkan dengan proses penggilingan [3]. Penggunaan abu canggkang kelapa sawit berukuran partikel $7,4 \mu \mathrm{m}$ dapat mensubstitusi semen pada campuran beton sebesar 20\% - 30\%. Hasil kuat tekan yang diperoleh setara dengan campuran beton tanpa abu canggkang kelapa sawit, sedang durbilitasnya menunjukkan peningkatan [25],[28]. Sebagaimana halnya dengan abu sekam padi, Tabel 3 memperlihatkan bahwa kandungan silika dalam abu cangkang kelapa sawit juga lebih tinggi dibanding semen.

Tabel 3: Komposisi kandungan kimia semen dan abu canggkang kelapa sawit

\begin{tabular}{|c|c|c|c|c|c|c|c|c|c|}
\hline Komposisi kimia & $\mathrm{SiO}_{2}$ & $\mathrm{Al}_{2} \mathrm{O}_{3}$ & $\mathrm{Fe}_{2} \mathrm{O}_{3}$ & $\mathrm{MgO}$ & $\mathrm{CaO}$ & $\mathrm{Na}_{2} \mathrm{O}$ & $\mathrm{K}_{2} \mathrm{O}$ & $\mathrm{SO} 3$ & LOI \\
\hline Semen & 20,90 & 4,80 & 3,40 & 1,20 & 65,40 & 0,20 & 0,40 & 2,70 & 1,00 \\
\hline Abu canggkang & 65,3 & 2,6 & 2 & 3,1 & 6,4 & 0,3 & 5,7 & 0,5 & 10,1 \\
\hline
\end{tabular}

Sumber: Sata, V., et.al., 2004. 


\subsubsection{Limbah kaca}

Kaca adalah material transparan yang diproduksi dari peleburan silaka, soda dan $\mathrm{CaCO}_{3}$ pada suhu tinggi kemudian didinginkan sehingga menjadi padat. Kaca banyak ditemui sebagai limbah dalam bentuk botol, pecahan kaca, alat-alat rumah tangga, dan tabung vakum (tabung TV). Limbah kaca merupakan nonbiodegradable (tidak dapat terurai) yang menimbulkan masalah sebagai limbah padat dan tidak ramah lingkungan [26].

Penggunaan limbah kaca sebagai material konstruksi dapat menurunkan masalah lingkungan yang ditimbulkannya. Tepung limbah kaca dengan partikel $38 \mu \mathrm{m}$ mengandung silika tinggi yang bersifat sebagai material pozzolan. Penggunaan tepung kaca dalam campuran beton memberikan dampak baik pada sifat-sifat mekanis dan durabilitas beton. Sementara itu, apabila limbah kaca digunakan untuk aggregate halus, akan menghasilkan kemudahaan kerja (workability) yang lebih baik [26].

\section{Metode Penelitian}

\subsection{Rancangan campuran RPC}

Material yang akan digunakan dalam riset ini (rancangan campuran RPC) berupa:

- semen: tipe I merek Andalas,

- silica fume: merk SikaFume ${ }^{\circledR}$ dengan ukuran partikel 0,15 $\mu \mathrm{m}$ (pembanding),

- superplastisizer: merek Sika ${ }^{\circledR}$ ViscoCrete ${ }^{\circledR}$,

- Pasir halus ukuran partikel $150 \mu \mathrm{m}-600 \mu \mathrm{m}$;

- Tepung kuarsa ukuran partikel $10 \mu \mathrm{m}-45 \mu \mathrm{m}$ (pembanding);

- Tepung kaca dari limbah kaca lembaran dengan ukuran partikel $10 \mu \mathrm{m}-45$ $\mu \mathrm{m}$;

- Abu sekam padi ukuran partikel 0,45 $\mu \mathrm{m}-0,75 \mu \mathrm{m}$;

- Abu canggkang kelapa sawit ukuran partikel 0,45 $\mu \mathrm{m}-0,75 \mu \mathrm{m}$;

Sekam padi dan cangkang sawit terlebih dahulu dibakar pada suhu $700^{\circ} \mathrm{C}$. Kemudian abu sekam padi, abu canggkang kelapa sawit dan pecahan kaca akan digiling dengan mesin pembuat nano partikel high energy milling (HEM) E3D. Keseluruhan sampel tersebut selanjutnya akan diperiksa menggunakan scanning electron microscope (SEM), particle size analyzer (PSA), dan X-Ray Diffractometer (XRD).

Dalam upaya untuk menghasilkan packing density optimal, maka akan dilakukan beberapa eksperimental (trial mix) campuran RPC. Sebagai pedoman dasar dan pembanding, akan digunakan komposisi campuran sebagaimana yang digunakan dalam referensi [27]. Selanjutnya dirancang campuran yang komposisinya disesuaikan dengan karakteristik material abu sekam padi, abu canggkang kelapa sawit dan tepung kaca.

Berhubung belum tersedianya metode standar sebagai acuan dalam perancangan campuran RPC, maka komposisi campuran yang akan dibuat didasarkan pada cara eksperimen dan bersifat trial and error dengan berprinsip pada: 
a. Penggunaan faktor air semen (w/c ratio) ekstrim rendah $(0,19-0,26)$ sehingga memenuhi target kekuatan $\geq 120 \mathrm{MPa}$ dengan workabilitas yang baik.

b. Mengoptimalkan packing density agregat gabungan antara fraksi pasir halus dengan tepung kaca dan abu sekam padi/abu canggkang kelapa sawit.

Berdasarkan pada kedua hal di atas dan melalui pendekatan dengan metode absolute volume [21], maka untuk mendapatkan komposisi masing-masing material dalam $1 \mathrm{~m}^{3}$ beton dapat dilakukan berdasarkan Persamaan (1):

$$
\frac{W}{1000}+\frac{C}{1000 \rho_{\varepsilon}}+\frac{A_{1}}{1000 \rho_{1}}+\frac{A_{2}}{1000 \rho_{2}}+\frac{A_{3}}{1000 \rho_{3}}=1
$$

Dalam hal ini: $\mathrm{W}$ adalah berat air, $\mathrm{C}$ adalah kebutuhan semen dan $\mathrm{A}_{1}, \mathrm{~A}_{2}$ dan $A_{3}$ masing-masing adalah fraksi agregat, serta $\rho$ merupakan densitas dari masing-masing material. Dengan menetapkan rasio air/semen dan rasio agregat/semen maka komposisi material-material penyusunnya dapat ditentukan.

\subsection{Pengujian Sifat-sifat mekanis RPC}

Pengujian sifat mekanis hasil trial mix dilakukan dengan 16 benda uji silinder standar $150 \mathrm{~mm}$ x $300 \mathrm{~mm}$ untuk masing-masing pengujian: kuat tekan (compressive strength), kuat tarik belah (tensile strength) modulus elastisitas (modulus of elasticity), susut pengeringan (draying shrinkage), dan permaebilitas (permeability). Kemudahan kerja (workability) diukur dengan pengujian flow table.

\subsection{Pengujian Durabilitas RPC}

Pengujian durabilitas yang akan dilakukan terhadap hasil trial mix RPC berupa:

a. Ketahanan terhadap klorida, yaitu dalamnya penetrasi klorida, diuji dengan perendaman dalam larutan $3 \% \mathrm{NaCl}$;

b. Ketahanan terhadap asam berupa persentase kehilangan berat, diuji dengan perendaman dalam larutan $3 \% \mathrm{HCl}$;

c. Ketahanan terhadap sulfat berupa persentase kehilangan berat, diuji dengan perendaman dalam larutan $3 \% \mathrm{H}_{2} \mathrm{SO}_{4}$.

\section{Diskusi}

Penggunaan RPC pada konstruksi dapat memberikan beberapa keunggulan dibandingkan dengan beton konvensional, antara lain:

(i) Superior dalam hal kuat tekan: kuat tekan RPC 4 kali lebih besar dibandingkan kuat tekan beton normal, sehingga dapat mereduksi beban mati dengan demensi struktur yang lebih ramping. Struktur RPC memiliki bobot antara 1/3 - 1/2 dari bobot struktur konvensional. Reduksi dimensi struktur akan mengurangi biaya total struktur dan meningkatkan daya guna ketinggian lantai pada gedung bertingkat tinggi [4],[23],;

(ii) Superior dalam hal daktilitas: daktilitas RPC rata-rata 300 kali lebih besar dibanding high performance concrete (HPC) yang menggunakan agregat 
kasar, memberikan tingkat keandalan (reliability) struktur yang lebih besar bahkan pada kondisi beban berlebih atau beban gempa [16];

(iii) Superior dalam hal durabilitas (keawetan): durabilitas RPC yang tinggi berdampak pada berkurangnya biaya perawatan. Tingkat impermaebilitas RPC hampir mendekati kedap air/udara, memberikan daya tahan terhadap karbonisasi, penetrasi klorida dan penetrasi sulfat. RPC memiliki ketahanan aus tinggi yang dapat meningkatkan umur penggunaan lantai jembatan dan lantai industri. RPC juga memiliki daya tahan tinggi terhadap korosi sehingga memberikan perlindungan yang cukup baik dalam lingkungan yang ekstrim [14];

(iv) Tanpa tulangan baja: RPC meng-eleminasi penggunaan tulangan baja, hal ini mengurangi biaya buruh yang dipakai untuk merakit dan memasang tulangan. Juga memberikan keleluasaan desain elemen struktur tanpa ada pembatasan ukuran penampang [4],[7],[8];

(v) Mereduksi ketebalan elemen beton: memberikan keuntungan pada penghematan material dan biaya [31];

(vi) Kualitas permukaan beton sangat halus [7].

Disamping memberi beberapa keunggulan, RPC juga memiliki beberapa kelemahan, berupa:

(i) Kandungan semen tinggi: berat semen dalam RPC berkisar antara 800 $1000 \mathrm{~kg} / \mathrm{m}^{3}$ (3 - 4 kali lebih besar dibanding beton normal) mengakibatkan biaya produksi tinggi dan menghasilkan efek negatif dari panas hidrasi yang menyebabkan masalah susut [31].

(ii) RPC secara umum mahal, dan tidak dapat menggantikan beton konvensional pada keseluruhan aplikasi. Hal ini terjadi apabila campuran beton konvensional telah memenuhi kriteria kinerja (performance) dengan biaya yang lebih ekonomis [7].

Mengingat banyaknya keunggulan RPC dibanding beton konvensional dan belum berkembang riset tentang RPC di Indonesia, maka dibutuhkan suatu riset untuk mengembangkan RPC bermaterial lokal Indonesia, dengan sumber silika berasal dari material organik berupa: abu sekam padi (rice husk ash) dan abu canggkang kelapa sawit (palm oil fuel ash). Kedua material tersebut didapat dengan cara pembakaran dan penggilingan limbah produk pengolahan hasil pertanian/perkebunan yang cukup banyak tersedia di Provinsi Aceh. Dalam riset ini juga akan digunakan tepung kaca yang diolah dari limbah kaca (beling) sebagai pengganti tepung kuarsa (crushed quartz/quartz powder). Dengan penggunaan material limbah, diharapkan dapat dihasilkan RPC dengan biaya produksi lebih ekonomis dan mengurangi dampak negatif limbah terhadap lingkungan.

Tujuan utama dari riset ini adalah untuk mendapatkan komposisi RPC bermaterial pozzolan dari limbah bahan organik dan limbah kaca dengan metode eksperimental guna menghasilkan nilai packing density optimal, serta untuk mengetahui:

- sifat-sifat mekanis RPC berupa: kemudahan kerja (workability), kuat tekan (compressive strength), kuat tarik belah (tensile strength) modulus elastisitas 
(modulus of elasticity), susut pengeringan (draying shrinkage), dan permaebilitas (permeability);

- durabilitas RPC berupa ketahanan terhadap: klorida, sulfat, dan asam.

Tujuan lain dari riset ini adalah:

a. Mengetahui persentase abu sekam padi dan persentase abu cangkang kelapa sawit maksimum yang dapat digunakan dalam masing-masing campuran yang menghasilkan kuat tekan dan workability terbaik;

b. Mengetahui efek dari pencampuran silica fume dan abu sekam padi; silica fume dan abu cangkang sawit; dan silica fume, abu sekam padi dan abu cangkang sawit terhadap kuat tekan dan workability;

c. Mengurangi dampak negatif limbah terhadap lingkungan dengan pemanfaatan sebagai bahan campuran RPC.

Adapun manfaat dari riset ini adalah memberikan kontribusi terhadap ketersediaan rancangan campuran RPC berbahan lokal Indonesia dengan biaya produksi yang lebih ekonomis. Selanjutnya hasil riset RPC ini dapat dijadikan produk industri lokal yang ramah lingkungan (green concrete) yang berdampak positif terhadap pengurangan limbah padat.

\subsection{Ucapan Terima Kasih}

Penulis menyampaikan terimakasih kepada Prof. Dr. Ir. Bustami Syam, M.S.M.E., dekan Fakultas Teknik Universitas Sumetera Utara, Prof. Dr. Ir. Bachrian Lubis, M.Sc., Prof. Dr. Ing. Johannes Tarigan, dan Dr. Ir. Ahmad Perwira Mulia, M.Sc., Dosen Jurusan Teknik Sipil, Fakultas Teknik Universitas Sumetera Utara, atas kritikan, koreksi dan masukan yang sangat berharga terhadap penulisan ini. Ucapan terimakasih juga disampaikan kepada Ir. T. Hafli, M.T., Dekan Fakultas Teknik Universitas Malikussaleh, dan Fasdarsyah, S.T., M.T., Ketua Jurusan Teknik Sipil Universitas Malikussaleh, atas dukungan yang diberikan.

\section{Daftar Kepustakaan}

[1] Allena, S., and Newtson, C.M., 2010, Ultra-High Strength Concrete Mixtures Using Local Materials, Concrete Sustainability Conference, National Ready Mixed Concrete Association;

[2] Arunachalam. K., and Vigneshwari, M., 2011, Experimental Investigation on Ultra High Strength Concrete Containing Mineral Admixtures Under Different Curing Conditions, International Journal of Civil And Structural Engineering, Vol. 2, No. 1, pp. 34-42;

[3] Awal., A.S.M.A., and Husain, M.W., 1996, Palm Oil Fuel Ash-As Potential Pozzolanic in Concrete construction, in Proceedings of International Conference on Urban Engineering in Asia Cities in the $21^{\text {st }}$ Century, Bangkok, Thaland, pp. D361-D366;

[4] Blais, P.Y., and Couture, M., 1999, Precast, Prestressed Pedestrian Bridge - World's First Reactive Powder Concrete Structure. PCI Journal, Vol. 44, pp. 60-71; 
[5] Chan, Y.W., and Chu, S.H., 2004, Effect of Silica Fume on Steel Fiber Bond Characteristics in Reactive Powder Concrete, Cement and Concrete Research Vol. 34, pp. 1167-1172;

[6] Cheyrezy, M., Maret, V., and Frouin L., 1995, Microstructural Analysis of RPC (Reactive Powder Concrete), Cement and Concrete Research, Vol. 25, No. 7. pp. 1491-1500;

[7] Dauriac, C., 1997, Special Concrete May Give Steel Stiff Competition, The Seattle Daily Journal of Commerce, http://www.djc.com/special/concrete97/10024304.htm, diunduh 12 Januari 2013;

[8] Dowd, W., 1999, Reactive Powder Concrete: Ultra-High Performance Cement Based Composite, United States: Construction Innovation Forum;

[9] Dugat, J., Roux, N., and Bernier, G., 1996, Mechanical properties of Reactive Powder Concretes (RPC), Materials and Structures, Vol. 29, No. 4, pp. 233-240;

[10] Habel, K., et. al, 2006, Development of The Mechanical Properties of an Ultra-High Performance Fiber Reinforced Concrete (UHPFRC), Cement and Concrete Research, Vol. 36, pp.1362-1370;

[11] Hardjasaputra, H., 2009, Ultra High Performance Concrete - Beton Generasi Baru Berbasis Teknologi Nano,

http://wiryanto.files.wordpress.com/2009/08/6-harianto-hardjasaputramak.pdf, diunduh 12 Januari 2013;

[12] Hardjasaputra, H., 2010, The First Ultra High Performance Concrete in Indonsesia,

http://harianto.wordpress.com/2010/06/30/the-first-ultra-high-performanceconcrete-uhpc-in-indonesia/, diunduh 12 Januari 2013.

[13] Ji, T., Chen, C.Y., and Zhuang, Y.Z., 2012, Evaluation Method for Cracking Resistant Behavior of Reactive Powder Concrete, Construction and Building Materials Vo. 28 pp. 45-49;

[14] Ji, W.Y., et. al., 2008, Study on Reactive Powder Concrete Used in The Side Walk System of The Qinghai-Tibet Railway Bridg, Schmitz Ready Mix Inc.;

[15] Kartini, K. 2011, Rice Husk Ash - Pozzolanic Material for Sustainability, International Journal of Applied Science and Technology, Vol. 1, No. 6, pp. 169-178;

[16] Lee, N.P., and Chisholm, D.H., 2006, Study Report Reactive Powder Concrete, No. SR 146, BRANZ; Ltd,. Judgeford, New Zealand;

[17] Long, G., Wang, X., and Xie, Y., 2002, Very-High-Performance Concrete With Ultrafine Powders, Cement and Concrete Research, Vol. 32 pp. 601-605;

[18] Louis, L.M.A., 2010, Strength of Reactive Silica Sand Powder Concrete Made of Local Powders, Al-Qadisiya Journal For Engineering Sciences, Vol. 3 No. 3, pp. 234-243;

[19] Matte, V., and Moranville, M., 1999, Durability of Reactive Powder Composites: influence of silica fume on the leaching properties of very low water/binder pastes, Cement and Concrete Composites, Vol. 21, pp. 19 ; 
[20] Mishra, S., and Deodhar, S. V., 2011, Effect of Rice Husk Ash on Cement Mortar and Concrete,

http://www.nbmcw.com/articles/concrete/18708-effect-of-rice-husk-ash-oncement-mortar-and-concrete.html, diunduh 12 Januari 2013;

[21] Neville, A.M., 1983, Properties of Concrete, third edition, Longman Singapore Publisher, Singapore;

[22] Nematollahi, B., et. al., 2012, A Review on Ultra High Performance 'Ductile' Concrete (UHPdC) Technology, International Journal of Civil and Structural Engineering, Volume 2, No 3, pp. 1003-1018;

[23] Rebentrost, M., and Cavill, B., 2006, Reactive Powder Concrete Bridges, in: Austroads 6th bridge conference: bridging the gap. Perth, Western Australia, Australia, pp. 1-11;

[24] Richard, P., and Cheyrezy, M., 1995, Composition of Reactive Powder Concretes, Cement and Concrete Research, Vol. 25, No.7, pp. 1501-1511;

[25] Sata, V., et. al, 2004, Utilization of Palm Oil Fuel Ash in High-Strength Concrete, Journal of Materials in Civil Engineering, Vol. 16, pp. 623-628;

[26] Safiuddin, Md., et. al., 2010, Review: Utilization of Solid Wastes in Construction Materials, International Journal of the Physical Sciences Vol. 5, pp. 1952-1963;

[27] Tam, C.M., Tamb, V.W.Y., and Ng, K.M., 2012, Assessing Drying Shrinkage and Water Permeability of Reactive Powder Concrete Produced In Hong Kong, Construction and Building Materials Vol. 26 pp. 79-89;

[28] Tangchirapat, W., et. al., 2007, Use of Waste Ash from Palm Oil Industry in Concrete, Waste Management Journal, Vol. 27, Issue 1, pp. 81-88;

[29] Yanzhou, P., Shuguang H., and Qingjun, D., 2010, Preparation of Reactive Powder Concrete Using Fly Ash and Steel Slag Powder, Journal of Wuhan University of Technology-Matererial, Vol.25, No.2, pp. 349-355;

[30] Yazıci, H., 2007, The Effect of Curing Conditions on Compressive Strength of Ultra High Strength Concrete With High Volume Mineral Admixtures, Building and Environment, Vol. 42 pp. 2083-2089;

[31] Yazici, H., et. al., 2009, Mechanical Properties of Reactive Powder Concrete Containing Mineral Admixtures Under Different Curing Regimes. Construction and Building Material, Vol. 23, pp. 1223-1231;

[32] Yunsheng, Z., et. al, 2008, Preparation of C200 Green Reactive Powder Concrete and Its Static-Dynamic Behaviors, Cement \& Concrete Composites Vol. 30, pp. 831-838; 